\title{
Child friendly spaces impact across five humanitarian settings: a meta-analysis
}

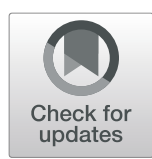

Sabrina Hermosilla', Janna Metzler ${ }^{1}$, Kevin Savage ${ }^{2}$, Miriam Musa $^{1}$ and Alastair Ager ${ }^{1,3^{*}}$ (D)

\begin{abstract}
Background: Humanitarian crises present major threats to the wellbeing of children. These threats include risks of violence, abduction and abuse, emotional distress and the disruption of development. Humanitarian response efforts frequently address these threats through psychosocial programming. Systematic reviews have demonstrated the weak evidence-base regarding the impact of such interventions. This analysis assesses the impact of Child Friendly Spaces (CFS), one such commonly implemented intervention after humanitarian emergencies.

Methods: We completed baseline and endline (three-six months post-baseline) assessments regarding protection concerns, psychosocial wellbeing, developmental assets and community resources for a total of 1010 children and 1312 carers in catchment areas for interventions with humanitarian populations in Ethiopia, Uganda, Iraq, Jordan, and Nepal. We estimated intervention effect-sizes with Cohen's $d$ for difference in mean difference scores between attenders and non-attenders - who proved comparable on baseline measures - by site. We then pooled findings for a meta-analysis summarizing overall impacts across domains.

Results: Amongst children aged 6-11, significant intervention impacts were observed through site-level analysis for protection concerns (Ethiopia, Cohen's $d=0.48,95 \% \mathrm{Cl} 0.08-0.88$ ), psychosocial wellbeing (Ethiopia, $d=0.51$,

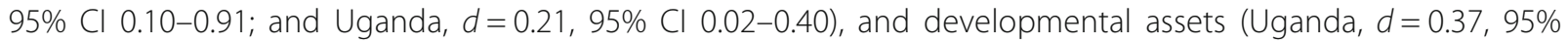
$\mathrm{Cl} 0.15-0.59$; and Iraq, $d=0.86,95 \% \mathrm{Cl} 0.18-1.54)$. Pooled analyses for this age group found impacts of intervention to be significant only for psychosocial wellbeing ( $d=0.18,95 \% \mathrm{Cl} 0.03-0.33$ ). Among children aged $12-17$, site-level analysis indicated intervention impact for protection concerns in one site (Iraq, $d=0.58,95 \% \mathrm{Cl} 0.07-1.09$ ), with pooled analysis indicating no significant impacts.
\end{abstract}

Conclusion: CFS can provide - albeit inconsistently - a protective and promotive environment for younger children. CFS show no impact with older children and in connecting children and carers with wider community resources. A major reappraisal of programming approaches and quality assurance mechanisms is required.

Keywords: Children, Youth, Psychosocial wellbeing, Mental health, Protection, Development, Assets, Resources, Humanitarian, Intervention

\section{Background}

Humanitarian crises present a broad range of protection risks for children. Conflict and natural disaster expose children to life-threatening events and substantive risks associated with family separation and displacement, including neglect, sexual exploitation and abduction [1]. Exposure to traumatic events and disruption of preexisting patterns of care bring further challenges to

\footnotetext{
* Correspondence: aa2468@columbia.edu; aager@qmu.ac.uk

${ }^{1}$ Columbia University, 1051 Riverside Drive, New York 10032, USA

${ }^{3}$ Institute for Global Health and Development, Queen Margaret University,

Edinburgh, Scotland EH21 6UU, UK

Full list of author information is available at the end of the article
}

psychosocial wellbeing [2]. Child Friendly Spaces (CFS) have become a standard approach to address the protection and psychosocial needs of children in the context of humanitarian emergencies, being included in several major intervention guidelines [3-5]. CFS are seen as a means of providing a temporary, safe environment in which children may establish some degree of normalcy supportive of their well-being in situations of extreme adversity $[5,6]$. CFS are attractive to practitioners wanting a scalable programme with adaptable and diverse activities that is easily deployable in challenging contexts and potentially cost effective [6-11]. CFS, typically 
established to operate for the first three to six months of a crisis (though potentially extending for longer periods), have recently been documented as part of humanitarian response across the Middle East (including Lebanon, Jordan, Turkey, and Iraq), sub-Saharan Africa (including South Sudan, Central African Republic, Democratic Republic of Congo, Uganda and Cameroon), south-east and south Asia (including the Philippines, India and Bangladesh) and Latin America (including Mexico, Peru and Brazil) [12].

Notwithstanding variation in implementation approach across contexts, the core aims of CFS programming are typically threefold $[7,13]$. First, CFS serve as a mechanism for protecting children from abuse, exploitation and violence by providing a safe environment following displacement and/or local disruption. Safety is provided through identification of a secure physical space - repurposed accommodation, tents or a purpose-built construction - and deployment of local adult facilitators to supervise children present. Second, CFS seek to promote children's psychosocial wellbeing and the resources available to them through structured activities organised by these local facilitators. Whether involving sports, games, songs, educational activities etc. or more specific psychosocial exercises, these seek to build personal resources such as self-esteem and emotional self-regulation as well as broader coping strategies. Third, CFS generally aim to strengthen local mechanisms for support, protection and care for children by serving as a focal point for engaging with parents and mobilising other community resources (including non-governmental providers and relevant civic and religious associations).

Despite widespread consensus on the intervention's key objectives and subsequent global adoption of its use in emergency settings, little robust evidence exists related to programmatic outcomes and impacts $[7,8]$. In a systematic review of published and grey literature, only ten studies were found meeting the inclusion criteria, with most displaying major design weaknesses that restricted the ability to robustly confirm positive change over time or attribute such change to programmatic efforts [7]. Recent broader review of the evidence base for humanitarian interventions addressing the mental health and psychosocial wellbeing of displaced populations echoes these findings, emphasizing the need for more rigorous, mixed methods research on the effectiveness of widely-used, group-based psychosocial interventions, particularly those aimed at children and adolescents, such as CFS [14-17].

\section{Methods}

The current paper draws upon data collected in the course of a series of country field studies completed in a collaboration by Columbia University and World Vision International, working with Save the Children, UNICEF and other members of the Child Protection Working Group of the UN Protection Cluster. By pooling analyses across five sites - spanning Africa, the Middle East and Asia, as well as contexts of both natural disaster and conflict-induced displacement - this paper provides the first robust estimate of the general impact of CFS as a humanitarian intervention.

\section{Intervention sites}

This paper draws on data from five CFS field studies in Ethiopia, Uganda, Iraq, Jordan, and Nepal (see Table 1) - described in detail elsewhere [18, 19]. Briefly, in the Buramino refugee camp Ethiopia, two CFS sites, with a focus on functional literacy and numeracy skills for children fleeing drought and conflict in Somalia, were evaluated from January-May 2012 [20]. In Uganda, eight CFS were evaluated within the Rwamwanja Resettlement Center, from October 2012-March 2013, where Congolese children escaping conflict primarily engaged in traditional song, dance, storytelling, and organized sports [21]. In the Domiz refugee camp of Iraq, one CFS was evaluated from September 2013 to March 2014, in which Syrian children escaping war engaged in activities such as music, sports, drawing, storytelling, drama, and dance [22]. Similarly, in Zarqa, Jordan, one CFS, which served Syrian children with activities primarily including drawing, handicrafts, puzzles, games, storytelling, singing, and drama, was evaluated from February to August 2014 [23]. In Nepal, 11 CFS serving children affected by the 2015 earthquakes, with activities including games, outdoor sports, creative activities, traditional song and dance, and various life skills were evaluated from March 2015 to May 2016 [24].

\section{Measures}

Measures were identified for four domains (see Table 2). For measures of protection concerns and knowledge of community resources, items were drawn from the Child Protection Rapid Assessment (CPRA, sections one and three respectively), an inter-agency tool designed for use following the rapid-onset of an emergency [25]. For measures of psychosocial wellbeing, a scale with established

Table 1 Data collection time period for included studies

\begin{tabular}{lll}
\hline Study & Data Collection Wave & \\
\cline { 2 - 3 } & Baseline (T1) & Endline (T2) \\
\hline Ethiopia & January 2012 & May 2012 \\
Iraq & September 2013 & March 2014 \\
Jordan & February 2014 & August 2014 \\
Nepal & May 2015 & November 2015 \\
Uganda & October 2012 & March 2013 \\
\hline
\end{tabular}

Table shows the start time of data collection by site and wave; data collection took on average four to six weeks to complete 
Table 2 Data collection tools by study

\begin{tabular}{|c|c|c|c|c|c|c|c|c|}
\hline \multirow[t]{3}{*}{ Study } & \multicolumn{8}{|c|}{ Data Collection Tools by Respondent Type } \\
\hline & \multicolumn{2}{|c|}{ Child Protection Concerns } & \multicolumn{2}{|c|}{ Psychosocial Wellbeing } & \multicolumn{2}{|c|}{ Developmental Assets } & \multicolumn{2}{|c|}{ Community Resources } \\
\hline & Caregiver & Child & Caregiver & Child & Caregiver & Child & Caregiver & Child \\
\hline Ethiopia & CPRA1 & CPRA1 & SDQ & SDQ & CRDA & B-DAP & & \\
\hline Uganda & CPRA1 & & CWB & & CRDA & & CPRA3 & \\
\hline Iraq & CPRA1 & CPRA1 & MEPS & MEPS & CRDA & EmDAP & CPRA3 & CPRA3 \\
\hline Jordan & CPRA1 & CPRA1 & MEPS & MEPS & CRDA & EmDAP & CPRA3 & CPRA3 \\
\hline Nepal & CPRA1 & CPRA1 & SMFQ & Hope & & EmDAP & CPRA3 & CPRA3 \\
\hline
\end{tabular}

CPRA Child Protection Rapid Assessment (section 1: child protection concerns, or 3: knowledge of community resources to address child protection concerns). CRDA Caregiver Rating of Developmental Assets. CWB Child Psychosocial Well-being. DAP Developmental Assets Profile (Emergency or Brief). Hope Child Hope Scale. MEPS Middle East Psychosocial Measure. SDQ Strengths and Difficulties Questionnaire. SMFQ Short Mood and Feelings Questionnaire

validity for the target population was identified: the Amharic version of the Strengths and Difficulties Questionnaire [26]; items drawn from a study of child wellbeing in Uganda [27]; an Arabic psychosocial measure developed for use in the Middle East [28]; and versions of the Short Mood and Feelings Questionnaire and Child Hope Scale validated for use in Nepal [29]. Measures of development assets drew upon the SEARCH Institute's Developmental Assets Profile [30], assessing the presence of internal and external assets supporting development. All measures were translated and back-translated between English and relevant local languages. Acceptable internal consistency was secured across studies for the majority of multi-item scales (Cronbach's alpha 0.7 or above, see Additional file 1). CFS attendance was established at endline via child or carer report and dichotomized to 'always' or 'frequent' attender and 'infrequent' or 'never' attender.

\section{Design}

At each site we completed baseline surveys with carers and children from households selected within the catchment area for a proposed CFS before the beginning of programme activities. Procedures to secure equi-probability of selection varied across sites to accommodate local conditions, but generally involved random selection of geographical areas within the catchment area, and then random selection of households within these selected areas [31]. If there was at least one child aged between 6 and 11 in the household, their primary caregiver was identified to be invited for interview with respect to that child (or a randomly selected child in that age range if there was more than one). If there was a child aged between 12 and 17 in the household, that child (or a randomly selected child in that age range if there was more than one) was invited to be interviewed. Informed by local child protection specialists' judgements of threshold age of consent, ethical approvals required some adjustments in these age cut-offs for self- or caregiver-interview across sites (see Additional file 2). Targeted sample sizes were determined using an established algorithm for detection of an anticipated effect size of between 0.20 and 0.30 , with a power of 0.80 and statistical significance of <.05 [32]. For endline assessment, we interviewed these same caregivers and children three to six months later, noting CFS attendance in the intervening period. Strategies to randomly allocate children to attendance and non-attendance conditions proved ethically and pragmatically challenging. Accordingly, comparability of attenders and non-attenders was established by statistical analysis of baseline characteristics. All interviews were completed in the relevant local language(s) by a trained local researcher with fluency in that language. Informed consent to be interviewed was secured verbally, with participants asked to make their 'mark' or provide their signature acknowledging willingness to participate. Written copies of the consent form in the relevant local languages were available. The study protocol was reviewed and approved by the Columbia University Medical Center IRB (Reference IRB-AAAJ4352) and relevant national authorities in each setting.

\section{Data analysis}

Two authors (SH and MM) extracted relevant information from original CFS study datasets, including child or adolescent's age, gender, CFS treatment status (intervention or control), and outcome related data (e.g., child protection concerns, psychosocial wellbeing, development assets, and community resources). We assessed the methodological quality of included studies, informed by the PRISMA Statement [33].

We conducted all data analyses in Stata 14. First, to estimate programme effect, we calculated crude Cohen's $d$ for each study site across all primary outcomes (recoded when necessary so a positive outcome is indicative of a salubrious programme effect), then stratified by age (under 12 and 12 and over age categories were selected across all study sites to be consistent with onset of adolescents in the literature, independent of respondent type) and gender. A Cohen's $d$ of 0.20 is considered a small effect, 0.50 a moderate effect, and 0.80 or above, a large effect [34]. Second, to estimate the effect across 
all sites, we conducted a random-effects meta-analysis with bootstrapped DerSimonian-Laird variance estimation for all primary outcomes and age and gender stratifications [35].

As CFS site inclusion was determined based on intervention rigor, from internal study documents rather than a published literature search, we did not conduct publication bias tests. We assessed heterogeneity across sites with both the $x^{2}$ test for heterogeneity (statistical significance at 0.05 ) and $I^{2}$ (50\% indicative of moderate heterogeneity).

\section{Role of the funding source}

The funders had no role in the design or conduct of data analyses, nor in interpretation of findings. SH, MM, JM, and AA had full access to all data and bear responsibility for publication.

\section{Results}

Across the five CFS field studies (Ethiopia, Uganda, Iraq, Jordan, and Nepal) we extracted baseline and endline (three to six months post-baseline) data on 1010 children and 1312 carers. Studied children ranged in age from six to seventeen. At baseline there were few statistically significant differences in age, gender, or outcome measures between CFS attenders and non-attenders (Table 3), supporting the validity of the latter as a counterfactual control condition. CFS programming across sites differed for younger and older children, thus we report age-stratified (under twelve years and twelve years and over) meta-analytic results. Sample size constraints prevented gender-stratified analyses from converging across more than two studies, and are thus not presented.

\section{Protection concerns}

In four of the five studies (see Fig. 1), CFS attendance was associated with a reduced reporting of protection concerns for caregivers of children aged 6-11, although only in the case of Ethiopia was this trend statistically significant (Cohen's $d=0.48,95 \%$ CI $0.08-0.88$ ). Pooled analysis suggested an overall weak, and statistically insignificant, intervention effect size of $0.13(-0.04,0.31$, $\left.I^{2}=46.35 \%\right)$ for this age group. For children aged twelve and older, the pooled Cohen's $d$ was $0.00(-0.30,0.30)$ and marked by significant heterogeneity $\left(I^{2}=63.42 \%\right.$, $p<.036)$. Only in Iraq was there a significant trend for reduced reporting of protection concerns amongst CFS attenders amongst this age group (Cohen's $d=$ 0.58, CI 0.07-1.09).

\section{Psychosocial wellbeing}

In four of the five studies (see Fig. 2), CFS attendance was associated with reports of better wellbeing amongst children aged 6-11. This trend was statistically significant in Ethiopia (Cohen's $d=0.51,95 \%$ CI $0.10-0.91$ ) and in Uganda (Cohen's $d=0.21$, 95\% CI 0.02-0.40). Pooled analysis suggested a small net intervention effect (Cohen's $d=0.18,95 \%$ CI $0.03-0.33$ ) for this age group. For children aged twelve and older, the pooled Cohen's $d$ was 0.12 $(-0.13,0.38)$, with no significant trend for better outcomes regarding psychosocial wellbeing amongst CFS attenders indicated at any site.

\section{Developmental assets}

In four of the five study sites, amongst children aged 611 greater positive impact on developmental assets was observed for those who had attended a CFS (see Fig. 3). This trend was statistically significant - with moderate to large effect size - in both Uganda (Cohen's $d=0.37$, 95\% CI 0.15-0.59) and Iraq (Cohen's $d=0.86,95 \% \mathrm{CI}$ $0.18-1.54$ ). Pooled analysis suggested an overall weak, statistically insignificant, and highly heterogeneous intervention effect of $0.19\left(-0.11,0.48, I^{2}=71.53 \%, p<.010\right)$ for this age group,

For older children, the pooled Cohen's $d$ was 0.08 $(-0.11,0.28)$, with no significant trend for better outcomes regarding developmental assets amongst CFS attenders indicated at any site.

\section{Knowledge of community resources}

Across Uganda, Iraq, Jordan, and Nepal (items were not used in first study in Ethiopia), there was no site where CFS attendance predicted greater knowledge of community resources (see Fig. 4). Pooled analysis accordingly indicated no statistically significant effect of CFS attendance on such knowledge for either age group (under 12: Cohen's $d-0.05$, 95\% CI: $-0.17-0.08 ; 12^{+}$Cohen's $d-$ 0.03 , 95\% CI: $-0.23-0.16)$.

\section{Discussion}

Our evidence across five field settings suggests that CFS can effectively address protection risks, threats to psychosocial wellbeing and support developmental assets amongst younger children. However, the extent to which targeted protective and promotive impacts are achieved by CFS varies widely across domains and settings.

The largest and most consistent evidence of impact is in relation to psychosocial wellbeing and developmental assets. The effect sizes on these measures, 0.18 and 0.19 respectively, represent modest but - with the large potential population influenced - substantive change of clear humanitarian consequence in terms of the mandate to reduce suffering and promote dignity [3639]. As noted, however, these pooled effect sizes reflect significant heterogeneity across settings. If the largest impacts identified were more consistently achieved this 


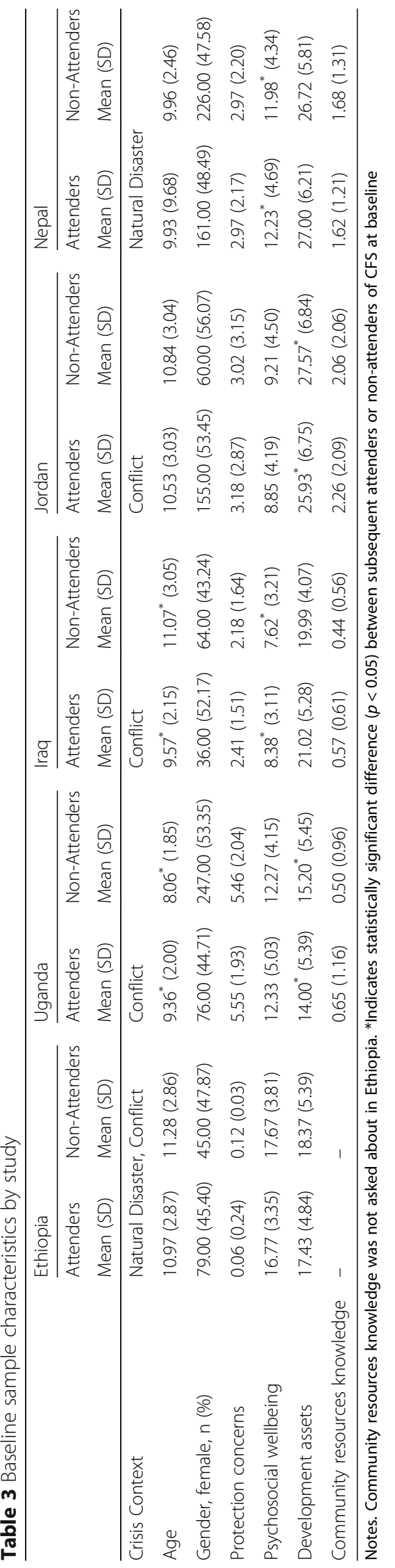




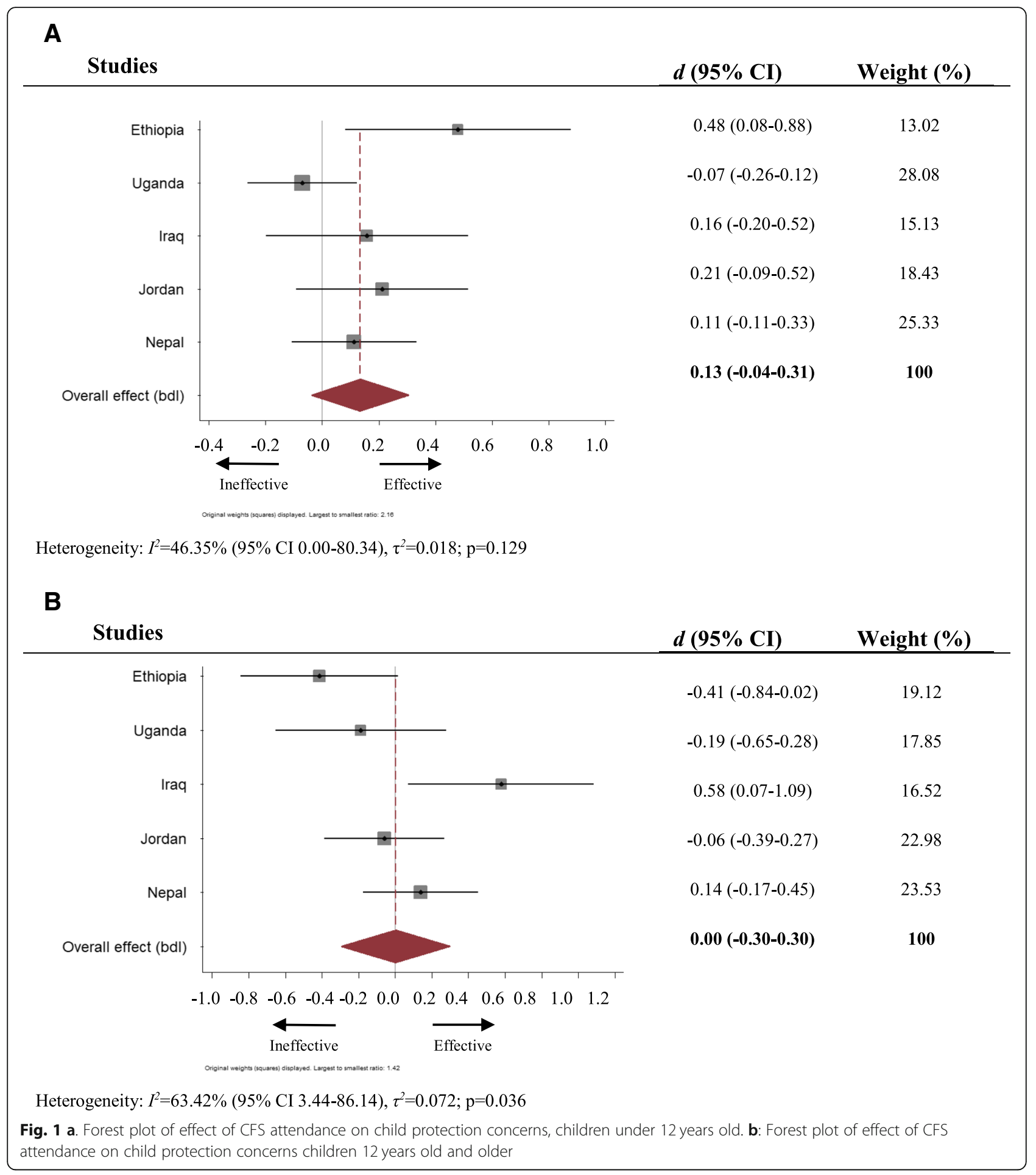

would transform CFS into an intervention with a moderate to high effect size. Establishing the basis for variation in outcomes is clearly a key priority for future systematic study. However, from field reports it appears likely that the orientation of activities, the quality assurance of programming and the influence of the site setting all play a potential role [18-24].
Impacts of CFS on child protection for younger children are overall more modest (with a pooled effect size of 0.13) but again important in humanitarian settings commonly marked by insecurity and with large populations of children [39]. Heterogeneity of impacts here is plausibly linked to the characteristics of programming and context. For example, the CFS in Ethiopia (where the largest effect 


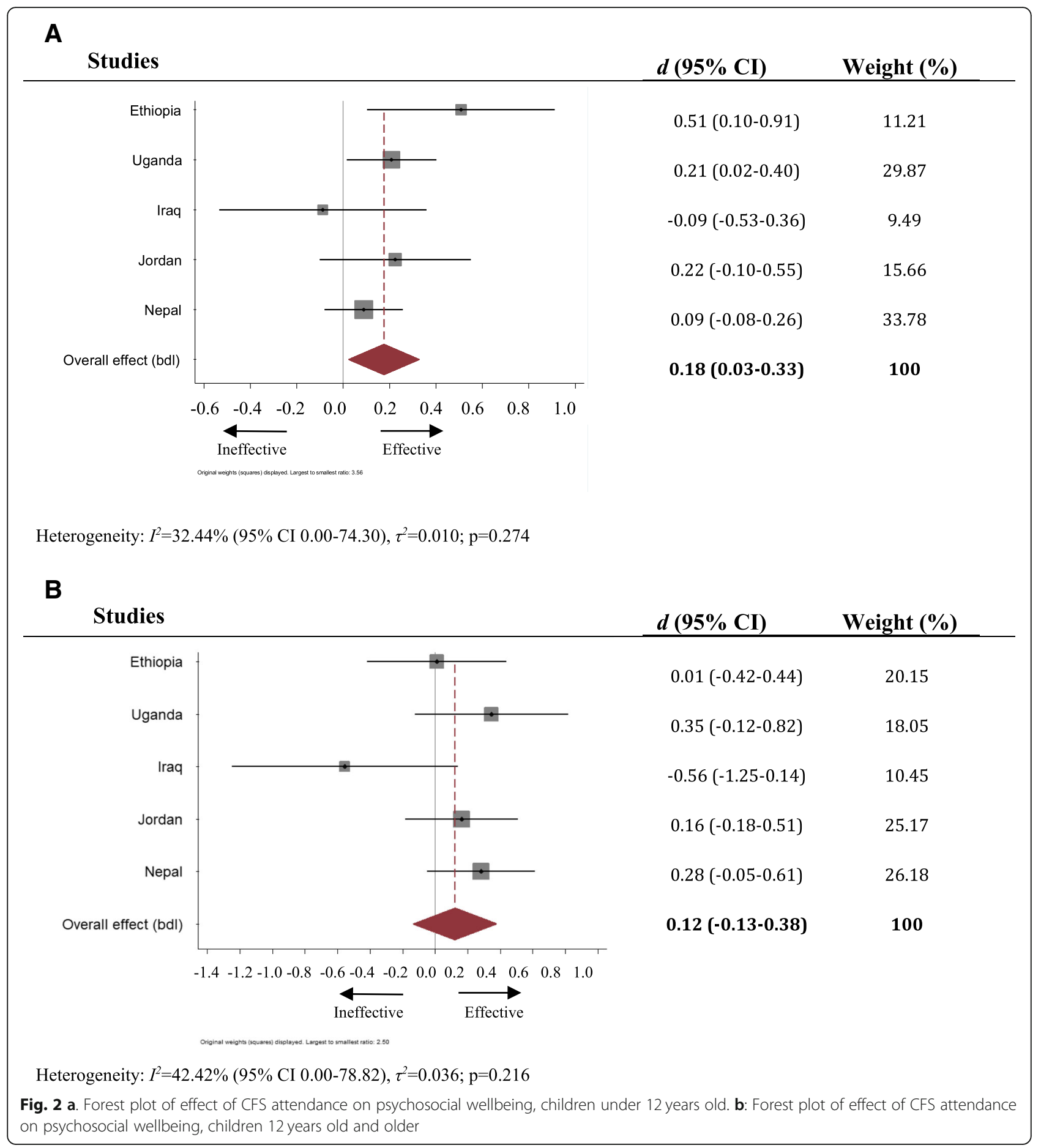

size of 0.48 was observed) secured sites with chain fences and employed security guards to separate children from external risks while attending; the CFS in Uganda (where the weakest effect was observed) were open sites less clearly demarked within the settlement [20,21]. Children and carers also identified some protection concerns in the wider environment over which CFS would feasibly have modest influence.
In the domain of knowledge of community resources there was no evidence of CFS impact on younger - nor older - children. With the potential for the benefits of knowledge gained through CFS (e.g. regarding organizations providing assistance or how to report protection concerns) to be shared within communities to non-attending households, it is possible that our research design was insensitive to broader community awareness established 


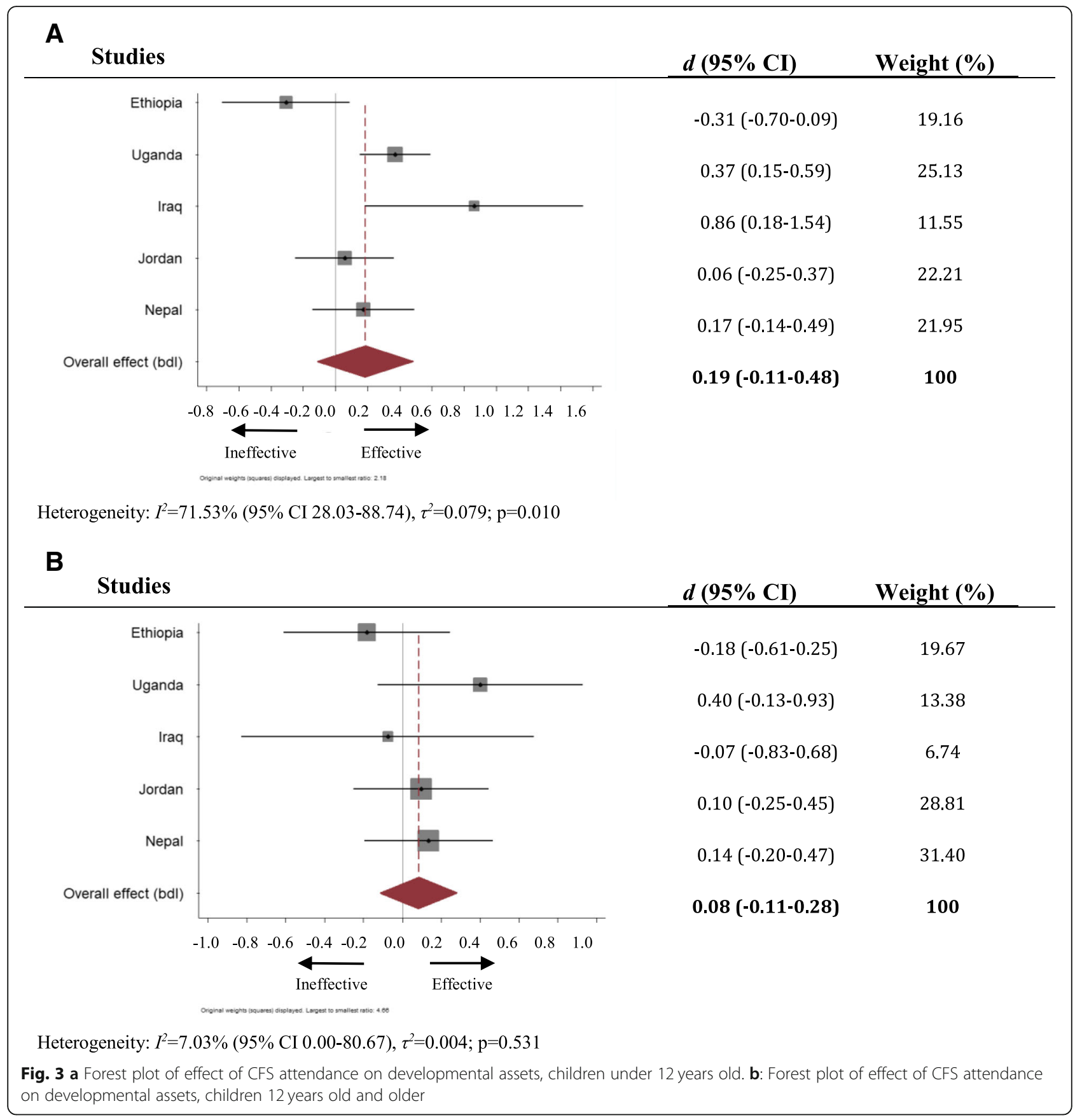

through CFS. However, with the non-significant trend actually towards greater knowledge amongst non-attenders than attenders there are weak grounds for assuming CFS to be a driver of such awareness.

Other than a small pooled effect (0.12) with regarding to psychosocial wellbeing, we found no evidence of CFS being an impactful intervention for older children across any domain. Engaging youth is recognised as challenging in humanitarian contexts given pressures on household livelihoods. However, Panter-Brick and colleagues [39] have recently documented moderate impacts (Cohen's d between 0.30 and 0.40 ) on insecurity, distress and well being of an eight-week profound stress atunement framework-informed programme of structured activities. This suggests that intervention approaches need to be more explicitly shaped to the interests and circumstances of youth if they are to be impactful in humanitarian settings.

Overall, given the dearth of rigorous evaluations of psychosocial interventions in emergency settings $[17,40]$ and the relatively wide-scale use of CFS, these findings provide valuable insight into the role that CFS are 


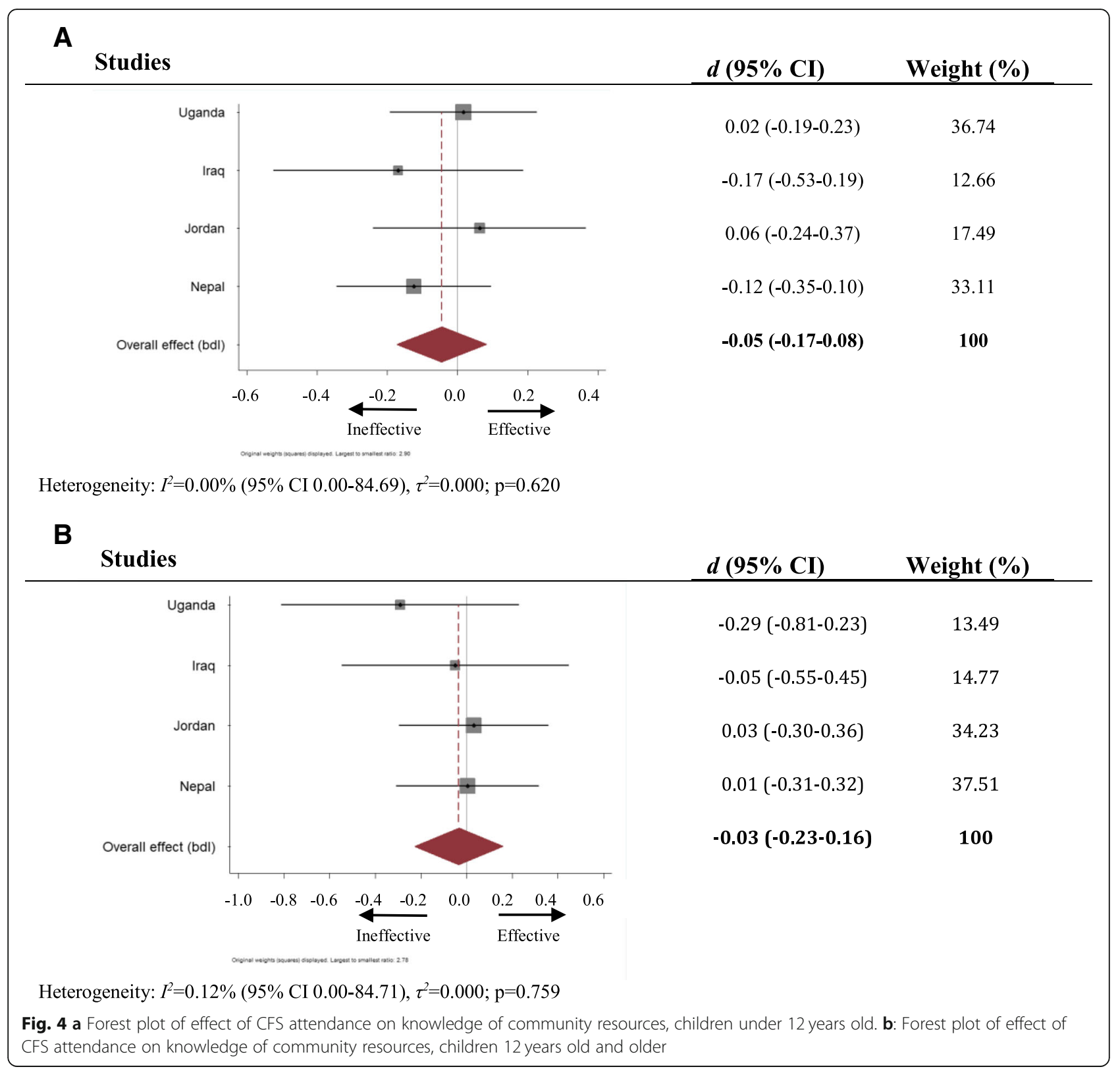

playing in the lives of tens of thousands of (younger) children and their families in the context of humanitarian emergencies. Critically, however, our study demonstrates that the impact of the intervention varies widely and is frequently below 'best in class' effectiveness. Research is required to elucidate the drivers of this variation. Field reports suggest that programme content, adaptation to context, and adherence to quality standards are likely key issues to focus upon [18]. For instance, the potential benefits of programming priorities addressing specific local circumstances, such as peace-building activities being incorporated into CFS in conflict-affected contexts or community mapping of earthquake 'safe' zones in post-earthquake settings, warrants exploration. Recently developed agency guidance for CFS in humanitarian settings [41], which has drawn upon the research studies reported here, posits an adequate supervisor-to-child ratio, attendance verification, forethought in activity planning and implementation, and a well-maintained safe play environment for children as hallmarks of quality CFS provision. Attention also needs to be paid to strategies to strengthen engagement of CFS - and other programming approaches with community resources in a way that will not only bolster intervention impact but also provide a sustainable basis for supporting longer-term impacts. This will require consideration of models of resource mobilization that foster localisation of humanitarian response from 
the earliest stages of an emergency. There is potential for such studies of comparative approaches to CFS to adopt cluster randomized control, or stepped wedge, designs that were not achievable for the current attender vs. non-attender analyses.

\section{Conclusions}

CFS can effectively address protection risks and threats to psychosocial wellbeing and support developmental assets amongst younger children. Effect sizes are modest but potentially valuable at the population level given the typically wide scale of implementation. However, these impacts are not consistently observed, suggesting the need for strengthened contextual adaptation and quality control and monitoring systems of implementing agencies. Impacts with older children, and on mobilization of community resources to support children, are notably weak, suggesting the need to consider alternative programming approaches if gains in these areas are to be secured.

\section{Additional files}

Additional file 1: Internal Consistency of Scales at Baseline by Respondent Type. (DOCX 23 kb)

Additional file 2: Age and Sample Size at Baseline by Respondent Type. (DOCX $23 \mathrm{~kb}$ )

\section{Abbreviations}

CFS: Child Friendly Spaces; CPRA: Child Protection Rapid Assessment

\section{Funding}

The research was funded by World Vision International, an elrha Research for Health in Humanitarian Crises (R2HC; elrha.org/r2hc) award funded equally by the Wellcome Trust and the UK Department for International Development, and additional funding from the National Institute of Mental Health T32MH096724. The funding sources had no role in the analysis or interpretation of this study.

\section{Availability of data and materials}

The datasets used during the current study are available from the first author on reasonable request.

\section{Authors' contributions}

$\mathrm{SH}$ participated in designing the study, conducted statistical analyses, and contributed to interpretation and drafting of manuscript. JM participated in designing the study and provided technical support for project coordination, tool development and translation, training on mobile survey technology, data collection strategy, data analysis, interpretation, and drafting the manuscript. KS participated in designing the study, provided overall leadership throughout its duration, and contributed to drafting the manuscript. MM participated in designing specific analyses, conducted statistical analyses, and contributed to drafting of manuscript. AA was lead investigator and responsible for the overall design and leadership of the study as well as supervision of project staff, data analysis and manuscript development. All authors read and approved the final manuscript.

\section{Ethics approval and consent to participate}

The overall study protocol was reviewed and approved by the Columbia University Medical Center IRB (Reference IRB-AAAJ4352) and relevant national authorities in each setting (Ethiopia: Government of Ethiopia, Administration for Refugee and Returnee Affairs; Iraq: UNICEF and the Ministry of Labour and Social Affairs; Jordan: Ministry of Social Development for the Hashemite
Kingdom of Jordan; Nepal: Child Protection Working Group, co-chaired by UNICEF and the Government of Nepal; and Uganda: Office of the Prime Minister of Uganda). Verbal informed consent and assent (under 18, with consent from caregiver) were collected from all study participants. IRBs approved verbal consenting procedures in recognition of the literacy levels of most participants.

\section{Consent for publication}

Not applicable

\section{Competing interests}

The authors declare that they have no competing interests.

\section{Publisher's Note}

Springer Nature remains neutral with regard to jurisdictional claims in published maps and institutional affiliations.

\section{Author details}

${ }^{1}$ Columbia University, 1051 Riverside Drive, New York 10032, USA. ${ }^{2}$ World Vision International, Chemin de Balexert 7-9, 1219 Châtelaine, Geneva, Switzerland. ${ }^{3}$ Institute for Global Health and Development, Queen Margaret University, Edinburgh, Scotland EH21 6UU, UK

Received: 11 January 2019 Accepted: 3 May 2019

Published online: 15 May 2019

\section{References}

1. Ager A, Blake C, Stark L, Daniel T. Child protection assessment in humanitarian emergencies: case studies from Georgia, Gaza, Haiti and Yemen. Child Abuse Negl. 2011:35:1045-52.

2. Reed $R$, Fazel $M$, Jones $L$, Panter-Brick C, Stein A. Mental health of displaced and refugee children resettled in low and middle-income countries: risk and protective factors. Lancet. 2011;379(9812):250-65.

3. Save the children. INEE toolkit: child friendly spaces facilitator training manual. London: save the children; 2008.

4. Child Protection Working Group. Minimum standards for child protection in humanitarian action. Geneva: child protection working group; 2012.

5. Global protection cluster, global education cluster, INEE, IASC. Guidelines for child friendly spaces in emergencies. UNICEF; 2011.

6. UNICEF. A practical guide for developing child friendly spaces. New York: UNICEF; 2009

7. Ager A, Meltzer J, Vojta M, Savage K. Child friendly spaces: a systematic review of the current evidence-base on outcomes and impact. Intervention. 2013;11(2):133-48.

8. Kostelny K, Wessells M. The protection and psychosocial well-being of young children following armed conflict: outcome research on child centered spaces in northern Uganda. The Journal of Developmental Processses. 2008;3(2):13-25.

9. Save the children. Community based child protection emergency project: internal evaluation report. London: save the children; 2011

10. Save the Children Sweden. Child friendly spaces handbook for animators (volunteers). North Darfur program. Stockholm: Save the Children Sweden; 2010.

11. World Vision International. Children in emergencies manual. In: Geneva WVl; 2006.

12. ReliefWeb. Updates 2019 [http://www.reliefweb.int/updates]. Accessed June 19, 2018.

13. Kostelny K, Wessells M. Child friendly spaces: promoting Children's resiliency amidst war. In: Fernando C, Ferrari M, editors. Handbook of resilience in children of war. New York: Springer; 2013. p. 119-29.

14. Tol WA, Barbui C, Galappatti A, Silove D, Betancourt TS, Souza R, et al. Mental health and psychosocial support in humanitarian settings: linking practice and research. Lancet. 2011;378(9802):1581-91.

15. Tol WA, Patel V, Tomlinson M, Baingana F, Galappatti A, Panter-Brick C, et al Research priorities for mental health and psychosocial support in humanitarian settings. PLoS Med. 2011:8(9):e1001096.

16. Blanchet $K$, Roberts $B$. An evidence review of research on health interventions in humanitarian crises. Final report. Harvard School of Public Health \& Overseas Development Institute; 2013.

17. Bangpan M, Dickson K, Felix L, Chiumento A. The impact of mental health and psychosocial support interventions on people affected by humanitarian 
emergencies: a systematic review humanitarian evidence programme. Oxford: Oxfam GB; 2017

18. Metzler J, Savage K, Yamano M, Ager A. Evaluation of child friendly spaces: an inter-agency series of impact evaluations in humanitarian emergencies. Columbia University mailman School of Public Health \& world vision international; 2015

19. Metzler J, Hermosilla S, Ager A. Longer-term mental health, developmenta and systems impacts of child friendly space interventions in humanitarian emergencies. Summary technical Report - October 2016 New York, NY: World Vision International \& Columbia University Mailman School of Public Health; 2016.

20. Metzler J, Savage K, Vojta M, Yamano M, Schafer A, Ager A. Evaluation of child friendly $\backslash$ spaces: Ethiopia field study summary report. World Vision International \& Columbia University Mailman School of public health; 2013.

21. Metzler J, Diaconu K, Hermosilla S, Kaijuka R, Ebulu G, Savage K, Ager A. Short- and longer-term impacts of child friendly space interventions in Rwanwanja refugee settlement, Uganda. J Child Psychol Psychiatry. in press.

22. Lilley S, Atrooshi A, Metzler J, Ager A. Evaluation of child friendly spaces: Iraq field study report - a save the children implemented CFS in Domiz refugee camp. World vision international, save the children, \& Columbia University mailman School of Public Health; 2015.

23. Metzler J, Ishaq M, Hermosilla S, Mumba E, Ager A. Evaluation of child friendly spaces Jordan field study report: a CFS implemented by world vision and partners in Zarqa, Jordan. World Vision International \& Columbia University Mailman School of public health; 2015.

24. Hermosilla S, Rodgers I, Bennett K, Napit Y, Meltzer J, Ager A. evaluation of child friendly spaces: Nepal final field study report - draft 12 June 2018. Columbia University \& World Vision Nepal; 2018.

25. Child Protection Working Group. Child protection rapid assessment toolkit. Geneva: global protection cluster; 2011.

26. Multicultural mental health resource Centre. Strengths and difficulties questionnaire. n.d. Available: https://www.multiculturalmentalhealth.ca/ clinical-tools/assessment/clinical-assessment-tools-for-children/strengthsand-difficulties-questionnaire-sdq/. Accessed Dec 32011.

27. Child Protection in Crisis Network. A Ugandan Childhood. Columbia University: New York; 2012. Available: http://www.cpcnetwork.org/wpcontent/uploads/2014/04/A-Ugandan-Childhood_CPC-Report_November2011.pdf. Accessed Aug 152018

28. UNICEF. Interagency Psychosocial Evaluation Report. Shuffat, East Jerusalem: UNICEF; 2011

29. Jordans, M., Komproe, I, Tol, W. Kohrt, B., Luitel, N.P. Macy, R. \&. de Jong, J.V. T.M. Evaluation of a classroom-based psychosocial intervention in conflictaffected Nepal: a cluster randomized controlled trial. J Child Psychol Psychiatry 51:7, 2010, pp 818-826.

30. Search Institute. User guide for The Developmental Assets Profile. Minneapolis; 2005.

31. Morris SK, Nguyen CK. A review of the cluster survey sampling method in humanitarian emergencies. Public Health Nurs. 2008;25(4):370-4.

32. UNICEF. Interagency guide to the evaluation of psychosocial programming in emergenices. New York; 2011.

33. Moher D, Liberati A, Tetzlaff J, Altman DG. Preferred reporting items for systematic reviews and meta-analyses: the PRISMA statement. Int I Surg. 2010:8(5):336-41.

34. Cohen J. Statistical power analysis for the behavioral sciences Routledge; 1977.

35. DerSimonian R, Laird N. Meta-analysis in clinical trials revisited. Contemporary Clinical Trials. 2015;45(Pt A):139-45.

36. Benson PL, Scales PC. Developmental assets. Encyclopedia of adolescence: springer; 2011. p. 667-83.

37. Scales PC, Roehlkepartain EC, Wallace T, Inselman A, Stephenson P, Rodriguez M. Brief report: assessing youth well-being in global emergency settings: early results from the emergency developmental assets profile. J Adolesc. 2015;45:98-102

38. Jordans MJ, Tol WA, Komproe IH, De Jong JV. Systematic review of evidence and treatment approaches: Psychosocial and mental health care for children in war. Child Adolesc Mental Health. 2009;14(1):2-14.

39. Panter-Brick C, Dajani R, Eggerman M, Hermosilla S, Sancilio A, Ager A. Insecurity, distress and mental health: experimental and randomized controlled trials of a psychosocial intervention for youth affected by the Syrian crisis. J Child Psychol Psychiatry. 2018;59(5):523-41.
40. Jordans MJ, Komproe $I H$, Tol WA, De Jong JT. Screening for psychosocial distress amongst war-affected children: cross-cultural construct validity of the CPDS. J Child Psychol Psychiatry. 2009;50(4):514-23.

41. Operational Guidance for Child Friendly Spaces in Humanitarian Settings. World vision international and IFRC reference Centre for Psychosocial Support. Copenhagen; 2018. Available: https://resourcecentre. savethechildren.net/node/12029/pdf/operational-guidance-for-child-friendlyspaces-low-res.pdf

\section{Ready to submit your research? Choose BMC and benefit from:}

- fast, convenient online submission

- thorough peer review by experienced researchers in your field

- rapid publication on acceptance

- support for research data, including large and complex data types

- gold Open Access which fosters wider collaboration and increased citations

- maximum visibility for your research: over $100 \mathrm{M}$ website views per year

At BMC, research is always in progress.

Learn more biomedcentral.com/submissions 